\title{
Crossing barriers towards improving cancer nanomedicine
}

\author{
Devika Chithrani* \\ Department of Physics and Astronomy, University of Victoria, Victoria, British Columbia, Canada; British Columbia Cancer agency, Victoria, British Columbia, \\ Canada
}

\section{Opinion}

The flexibility of cancer nanotechnology allows for the development of safer yet more effective nanoparticle-based tools for diagnostic and therapeutic applications in cancer research [1-3]. The ultimate goal of nanoparticle (NP)-based platforms will be the targeted delivery and monitoring of therapeutics to tumors while causing minimum side effects [4-8]. In addition to this, NP-based technology has the capability to develop novel multiplex systems to combine more than one treatment and imaging modalities for creating a more aggressive and effective approach in eradicating cancer $[3,9,10]$. The first generation of NP-based therapies approved by the FDA consists of lipid based NP-systems, such as liposomes and micelles [11]. However, more attention is given to the development of inorganic NP-based systems, such as gold NPs (GNPs) for drug delivery and therapeutics [12-15]. The successful delivery of NPs into tumor depends on efficiency of crossing few boundaries effectively which involves in vivo delivery, tissue transport, and internalization within individual tumor cells as discussed in this article.

\section{In vivo delivery of nanoparticles}

The rapid growth of tumor results in leaky vessels allowing NPs to permeate into the tumor. In addition, the NPs are retained due to the lack of a functional lymphatic system [16-18]. This Enhanced permeability and retention (EPR) effect has been exploited to passively accumulate NPs within tumors [16-18]. This process is known to be strongly dependent on the size of the NPs $[19,20]$. The lack of lymphatic drainage within the tumor also increase interstitial fluid pressure (IFP) which can also limit delivery of therapeutic agents [21]. Administration of agents that inhibit angiogenesis temporarily could improve the blood flow and reduce IFP by pruning immature vessels $[21,22]$.

\section{Penetration of nanoparticles through extracellular tumor matrix (ECM)}

A tumor with a well-developed collagen network can be considered to be physically resistant to transport of NP-based therapies $[23,24]$. Using in vitro tissue models, it was shown that NP transport is dependent on their size, tumor cell type, and surface functionality [25-27]. The more aggressive and invasive tumour cells secrete matrix-degrading proteinases that serve to break down collagen and attribute to the differences in ECM and cell layer organizations $[28,29]$. It was observed that the GNPs penetrated deeper through more aggressive tumor tissue models [25]. For tumors with a relatively welldeveloped collagen network, treatments that reverse or inhibit collagen production and assembly can be performed prior to NP-based therapies [23]. For example, Ji, et al. down-regulated ECM levels and observed an enhanced penetration of a therapeutic agent and suggested that the regulation of ECM may become a promising adjuvant therapeutic strategy for ECM-rich tumors [24]. Other studies have shown that ECM-degrading enzymes and hormones can be used to modify the collagen structure to further improve the distribution of NPs in solid tumors [30,31].

\section{Uptake of nanoparticles at individual cell level}

Cellular uptake of NPs is dependent on their size, shape, and surface properties. Among the size range 10-100 nm, NPs of diameter $50 \mathrm{~nm}$ have the highest uptake [32-34]. However, it is shown that adding polyethylene glycol (PEG) onto NP for in vivo applications would change the size dependent NP uptake dynamics at individual cell level. PEG is a commonly used molecule to decrease the NP surface exposure to proteins, such as opsonin, while improving the blood circulation of the NPs $[35,36]$.

The limitations of mortifying GNPs with PEG molecules is that accumulation at cellular level is decreased. This is due to the lowering of binding ability of NPs onto cell surface receptors [35-37]. Peptides containing the targeting moieties are being used to improve the accumulation of PEGylated NPs [36,38]. It was shown that the 50 $\mathrm{nm}$ was not the optimum size anymore and smaller NPs had a higher uptake. It is believed that the higher surface curvature of smaller NPs can expose targeting molecules to receptors on the tumor cell membrane.

It is known that in vitro data cannot be extrapolated directly to in vivo or clinical settings [39]. However, these in vitro models provide useful information in a less complex environment. As a first step in this direction, a recent study has shown that NP complexes optimized using in vitro models ultimately produced a higher accumulation within the tumor [27]. Accumulation of the NPs into the cells becomes a more complicated process as they must pass more barriers as discussed in this article. Successful clinical translation of nanomedicine requires NPs to be accumulated within the tumor cells [40].

${ }^{\star}$ Correspondence to: Chithrani D, Department of Physics and Astronomy, University of Victoria, Victoria, British Columbia, Canada, British Columbia Cancer agency, Victoria, British Columbia, Canada, E-mail: devikac@uvic.ca

Received: December 22, 2018; Accepted: December 28, 2018; Published: December 31, 2018 


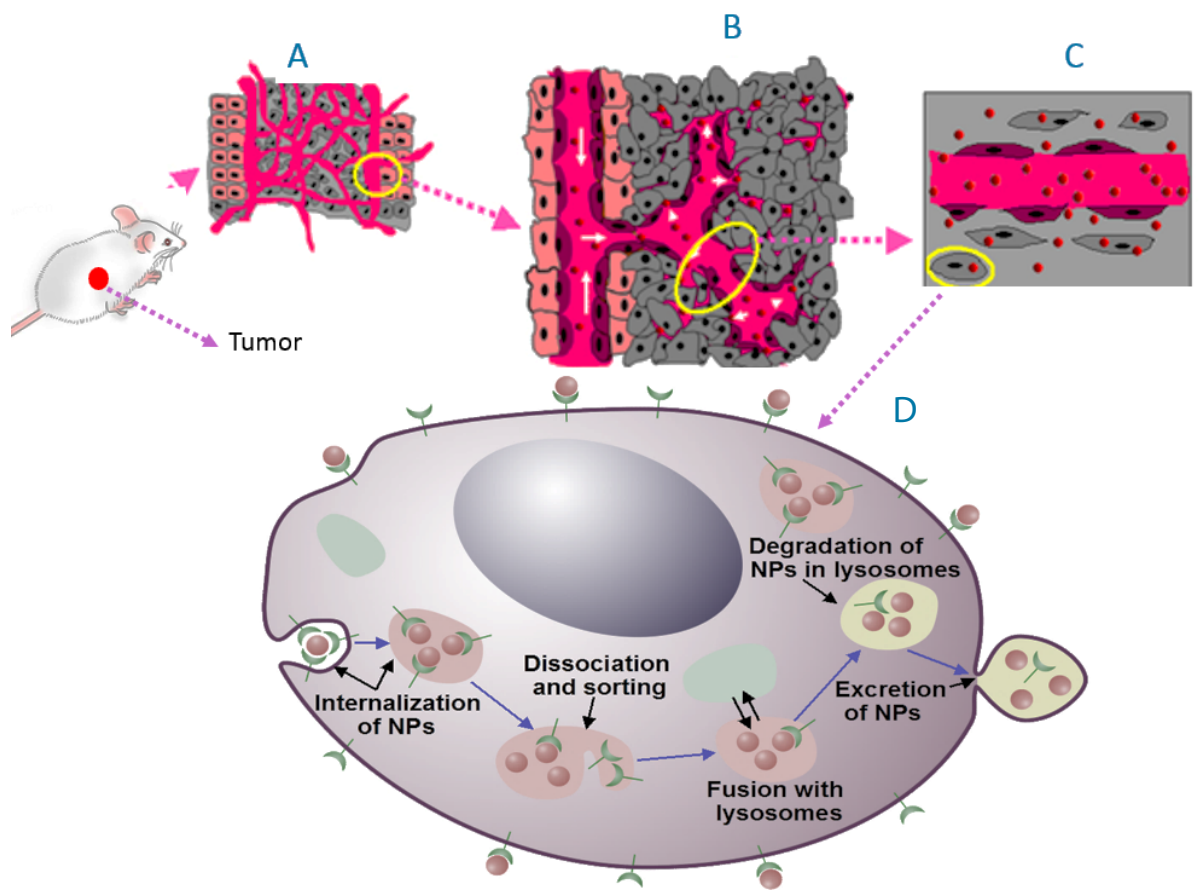

Figure 1. The successful delivery of NPs into tumor depends on optimizing size and surface properties at all three interfaces (in vivo delivery, tissue transport, and uptake at individual cell). (A) In vivo delivery. B-C) Reach tumor blood vessels and release of NPs into the tumor tissue through it leaky vasculature, respectively. D) Successful delivery at individual cell level.

\section{References}

1. Cuenca AG, Jiang H, Hochwald SN, Delano M, Cance WG, et al. (2006) Emerging implications of nanotechnology on cancer diagnostics and therapeutics. Cancer 107: 459-466.

2. Rao J (2008) Shedding Light on Tumors Using Nanoparticles. ACS Nano 2: 1984-1986.

3. Jelveh S, Chithrani BD (2011) Gold Nanostructures as a Platform for Combinational Therapy in Future Cancer Therapeutics. Cancer 3: 1081-1110.

4. Alivisatos P (2003) The use of nanocrystals in biological detection. Nat Biotech 22: 47-51.

5. Liong M, Lu J, Kovochich M, Xia T, Ruehm SG, et al. (2008) Multifunctional Inorganic Nanoparticles for Imaging, Targeting, and Drug Delivery. ACS Nano 2: 889-896.

6. Langereis S, Keupp J, van Velthoven JLJ, de Roos IHC, Burdinski D, et al. (2009) A Temperature-Sensitive Liposomal 1H CEST and 19F Contrast Agent for MR ImageGuided Drug Delivery. J Am Chem Soc 9: 1380-1381.

7. Perrault SD, Walkey C, Jennings T, Fischer HC, Chan WCW (2009) Mediating Tumor Targeting Efficiency of Nanoparticles Through Design. Nano Lett 9: 1909-1915.

8. Lee JE, Lee N, Kim H, Kim J, Choi SH, et al. (2010) Uniform Mesoporous DyeDoped Silica Nanocrystals for Simultaneous Enhanced Magnetic Resonance Imaging, Fluorescence Imaging, and Drug Delivery. J Am Chem Soc 132: 552-557.

9. Cai W, Gao T, Hong H, Sun J (2008) Applications of gold nanoparticles in cancer nanotechnology. Nanotechnol Sci Appl 1: 17-32.

10. Chithrani DB, Jelveh S, Jalali F, van Prooijen M, Allen C, et al. (2010) Gold nanoparticles as radiation sensitizers in cancer therapy. Radiat Res 173: 719-728.

11. Peer D, Karp JM, Hong S, Farokhzad OC, Margalit R, et al. (2007) Nanocarriers as an emerging platform for cancer therapy. Nat Nanotechnol 2: 751-760. [Crossref]

12. Chithrani DB (2010) Nanoparticles for improved therapeutics and imaging in cancer therapy. Recent Pat Nanotechnol 4: 171-180. [Crossref]

13. Yang C, Uertz J, Chithrani DB (2016) Colloidal Gold-Mediated Delivery of Bleomycin for Improved Outcome in Chemotherapy. Nanomaterials 6: 48.

14. Yang C, Bromma K, Sung W, Schuemann J, Chithrani D (2018) Determining the Radiation Enhancement Effects of Gold Nanoparticles in Cells in a Combined Treatment with Cisplatin and Radiation at Therapeutic Megavoltage Energies. Cancers 10: 150 .
15. Yang C, Bromma K, Di Ciano-Oliveira C, Zafarana G, van Prooijen M, et al. (2018) Gold nanoparticle mediated combined cancer therapy. Cancer Nanotechnol 9: 4.

16. Maeda H, Wu J, Sawa T, Matsumura Y, Hori K (2000) Tumor vascular permeability and the EPR effect in macromolecular therapeutics. J Control Rel 65: 271-284.

17. Dreher MR, Liu W, Michelich CR, Dewhirst MW, Yuan F, et al. (2006) Tumor Vascular Permeability, Accumulation, and Penetration of Macromolecular Drug Carriers. J Natl Cancer Inst 98: 335-344.

18. Farokhzad OC, Langer $\mathrm{R}$ (2009) Impact of nanotechnology on drug delivery. ACS Nano 3: 16-20. [Crossref]

19. Perrault SD, Walkey C, Jennings T, Fischer HC, Chan WCW (2009) Mediating Tumor Targeting Efficiency of Nanoparticles Through Design. Nano Lett 9: 1909-1915.

20. Zhang G, Yang Z, Lu W, Zhang R, Huang Q, et al. (2009) Influence of anchoring ligands and particle size on the colloidal stability and in vivo biodistribution of polyethylene glycol-coated gold nanoparticles in tumorxenografted mice. Biomaterials 30: 1928-1936.

21. Minchinton AI, Tannock IF (2006) Drug penetration in solid tumours. Nat Rev Cancer 6: 583-592. [Crossref]

22. Tong RT, Boucher Y, Kozin SV, Winkler F, Hicklin DJ, et al. (2004) Vascular normalization by vascular endothelial growth factor receptor 2 blockade induces a pressure gradient across the vasculature and improves drug penetration in tumors. Cancer Res 64: 3731-3736.

23. Netti PA1, Berk DA, Swartz MA, Grodzinsky AJ, Jain RK (2000) Role of extracellular matrix assembly in interstitial transport in sold tumors. Cancer Res 60: 2497-2503.

24. Ji T, Lang J, Wang J, Cai R, Zhang Y, et al. (2017) Designing liposomes to suppress extraceullular matrix expression to enhance drug penetration and pancreatic tumor therapy. ACS nano 11: 8668-8678.

25. Yohan D, Cruje C, Lu X, Chithrani D (2015) Elucidating the uptake and distribution of nanoparticles in solid tumors via a multilayered cell culture model. Nano-Micro Lett 7: $127-137$.

26. Yohan D, Cruje C, Lu X, Chithrani D (2015) Elucidating the Uptake and Distribution of Nanoparticles in Solid Tumors via a Multilayered Cell Culture Model. Nanomicro Lett 7: 127-137. [Crossref]

27. Yang C, Bromma K, Chithrani BD (2018) Peptide Mediated In Vivo Tumor Targeting of Nanoparticles through Optimization in Single and Multilayer In Vitro Cell Models. Cancers 10: 84 
28. Liotta LA, Thorgeirsson UP, Garbisa S (1982) Role of collagenases in tumor cell invasion. Cancer Metastasis Rev 1: 277-288. [Crossref]

29. J Gross, Y Nagai, Specific degradation of the collagen molecule by tadpole collagenolytic enzyme, Proceedings of the National Academy of Sciences, 54 (1965) 1197-1204

30. Jain RK, Stylianopoulos T (2010) Delivering nanomedicine to solid tumors. Nat Rev Clin Oncol 7: 653-664.

31. Goodman TT, Peggy LO, Pun SH (2007) Increased nanoparticle penetration in collagenase-treated multicellular spheroids. Int J Nanomedicine 2: 265-274.

32. Chithrani BD, Ghazani AA, Chan WC (2006) Determining the size and shape dependence of gold nanoparticle uptake into mammalian cells. Nano Lett 6: 662-668. [Crossref]

33. Chithrani DB (2010) Intracellular uptake, transport, and processing of gold nanostructures. Mol Membr Biol 27: 299-311. [Crossref]
34. Chithrani DB (2011) Optimization of bio-nano interface using gold nanostructures as a model nanoparticle system. Int Sciences J 1: 115-135.

35. Cruje C, Chithrani DB (2014) Polyethylene Glycol Functionalized Nanoparticles for Improved Cancer Treatment. Rev Nanosci Nanotechnol 3: 20-30.

36. Cruje C, Chithrani B (2015) Integration of peptides for enhanced uptake of PEGylayed gold nanoparticles. J Nanosci Nanotechnol 15: 2125-2131.

37. Khawar IA, Jung KH, Jeong KH (2015) Improving drug delivery to solid tumors: Priming the tumor microenvironment. J Control Rel 201: 78-89.

38. Cruje C, Yang C, Uertz J, van Prooijen M, Chithrani BD (2015) Optimization of PEG coated nanoscale gold particles for enhanced radiation therapy. RSC Adv 5: 101525-101532.

39. Hill RPB, Robert B (2008) The scientific basis of radiotherapy, McGraw-Hill, Toronto, pp: 289-321.

40. Bae YH, Park K (2011) Targeted drug delivery to tumors: myths, reality and possibility. J Control Release 153: 198-205. [Crossref]

Copyright: (C2018 Chithrani D. This is an open-access article distributed under the terms of the Creative Commons Attribution License, which permits unrestricted use, distribution, and reproduction in any medium, provided the original author and source are credited. 